\title{
The important of physical activities in our life
}

\section{Introduction}

About 50 per cent of Malaysian citizens are at least overweight or obese," said Malaysian Health Minister, Dr S. Subramaniam. ${ }^{1}$ As we all know, physical activity (PA) has a very important meaning for everyone, it is one of the ways to health, and there are a lot of different activities for us to choose, it can be costly, it can be free of charge. If everyone involve in physical activity, may be the problem of overweight and obesity can be avoid. PA is important for health and longevity. However, statistically, Malaysia is the most obese country in Asia with an obesity rate of more than $45.3 \%$.

Maintaining regular exercise every day can bring many benefits to everyone. Of course, it is a healthy body and strength. Exercise also can be effective in improving the mental wellbeing of the general public, largely through improved mood and self-perceptions. ${ }^{2}$ Physical activity including exercise can indirectly improve subjective well-being and life quality by keeping disease and premature death at bay, there has recently been an increasing interest in its direct role in the prevention and treatment of mental health problems. ${ }^{2}$ Without physical activity, the body muscles will gradually lose their strength, endurance and ability to function properly. Through regular activities to keep all parts of the body in continuous activity, so that you are at a healthy level.

At the same time, regular exercise can also relieve stress and anxiety. When we come back from work or school every day, we are exhausted for a whole day work, but if we can go out to have a walk or jog at least 30 minutes, it can make us feel happy and the stress relief. A number of studies have found that exercise helps depression. The pressure of life can be expressed through sports or simple activities. Moreover, those who can maintain regular exercise will also reduce their chances of seeing a doctor.

Performing physical activity on a regular basis will help to improve overall health and fitness, as well as decrease the risk for many chronic diseases. ${ }^{3}$ Thus, physical activity is very important in our life.

\section{Physical activities}

Physical activity is defined as "bodily movement that is produced by the contraction of skeletal muscles and that substantially increase the amount of energy expend". ${ }^{4}$ According to Caspersen et al., ${ }^{5}$ the elements of physical activity are a) bodily movement via skeletal muscle; b)results in energy expenditure; c)Energy expenditure (kilocalories) varies continuously from low to high; and d)positively correlated with physical fitness. Physical activity including sports and exercise as well. Anyone involved in sports and exercise, they will use skeletal muscle and energy. There are many benefits if involved in sports and exercise. For example, it can be increase our healthy level and reduce the health problems.

Regular moderate intensity physical activity-such as walking, cycling, or participating in sports-has significant benefits for health. All young people should participate in physical activity of at least moderate intensity for at least $0.5 \mathrm{~h}$ per day. ${ }^{6}$ Physical activity not only reduces the risk of various non-communicable chronic diseases, but also is essential to enhance personal health. For instance, it can reduce the risk of cardiovascular diseases, diabetes, colon and breast cancer, stroke, hypertension, type 2 diabetes mellitus, osteoporosis,
Volume 3 Issue 4 - 2018

\author{
Syed Kamaruzaman Syed Ali \\ Faculty of Physical Education and Health, University of Malaya, \\ Malaysia
}

Correspondence: Syed Kamaruzaman Syed Ali, Faculty of Physical Education and Health, University of Malaya, Malaysia, Email syedkamaruzaman@gmail.com

Received: June 27, 2018 | Published: July 24, 2018

obesity, colon cancer, breast cancer, cognitive impairment, anxiety, and depression. ${ }^{7}$ Moreover, adequate levels of physical activity will decrease the risk of a hip or vertebral fracture and help control weight. However, lack of physical activity is already one of the global issues. Lack of physical activity is now a global health hazard and is increasing rapidly in both developed and developing countries. ${ }^{8}$

Physical activity is any activity that consumes physical energy, including walking, walking up and down the stairs, doing housework, etc. I am here just to share about only physical activity, not necessarily sports. Sports training are a planned, structured, and repetitive activity. We just need to go through physical activity to put our bodies at a healthy level. Sometimes people will misunderstand the difference between sports and physical activity, when the person talking about "sports", it will be associated with many different levels of training, it will be very tiring and difficult.

According to Malaysian Dietary Guidelines, physical activity has three main components:

1. Occupational work: Activities undertaken during the course of work.

2. Household and other chores: Activities undertaken as part of day to day living.

3. Leisure-time physical activity: Activities undertaken in the individual's discretionary or free time.

Malaysian Dietary Guidelines also shown that physical activity level (PAL) is a method of quantifying or characterising physical activity, commonly according to its type, frequency, duration and intensity. ${ }^{9}$

\section{Why physical activities?}

Physical education, sports and co-curriculum is a must in every school as it is an important element to produce individuals who are intellectually, spiritually, emotionally and physically balanced and harmonic, based on a firm belief in and devotion to God (The National Education Philosophy).

Therefore, starting from primary school, Physical Education class is a compulsory subject in school. This subject cannot be replacing by any others subject as it is the only physical exertion for students. In the same time, students gain a healthy body and learn values (such as cooperation, respect, leadership, sportsmanship etc.) in this class. 
In addition to being the designated subject of the school, the most important point for physical education is to cultivate the habit of exercise from a young age. Only by instilling the concept of exercise through physical education, to let the students understand that longterm regular exercise can improve physical fitness, improve personal health, and reduce the risk of getting diseases. Diseases or health problem that caused by lack of exercise include diabetes, cancer, cardiovascular diseases, stroke, high blood pressure, high blood cholesterol etc.

\section{Who will need physical activities?}

Health benefits occur for children and adolescents, young and middle-aged adults, older adults, and those in every studied racial and ethnic group. It also benefits for people with disabilities. Even a newborn baby need adult to help out on stretching, massage for their hands and legs muscle.

\section{What kind of physical activities?}

The simplest activity that everyone can start from is doing house work such as sweeping and mopping floor. This is the daily work for housewife and kind of exercise too. The least costly exercise is taking a walk or jogging outside of your home. Another suggestion is download the applications (Apps) from smart phone, there are many different work out Apps for smart phone users. All these Apps already have their own setting and users just need to follow their steps to complete each work out (Figure 1).

Below is one of the Apps samples that I would like to suggest as it is starting for a simple level that everyone can complete it. Every human being needs encouragement and satisfaction. Therefore, the advantages of this App are it has separated into different levels, from easy, medium to hard. Each level contains 2 stages for users to complete. Users can start from the easy level stage 1, to maintain for a 30 days exercise. If exercise begins with difficult level, it will undermine the determination of those who are trying to start exercising (Figure 1)

Even YouTube provides many workout videos for us to exercise from home without any equipment. The key point is choosing a suitable video and follows the whole exercise. An effective physical exercise is not necessarily to maintain 30 minutes of non-stop exercise. We can choose a combination of physical activity, each combination to maintain 10 minutes. We can have a short rest after recovery and then continue the second combination. These three consecutive combinations can also achieve the effect of exercise (Figure 1).

There is another choice for adult to have exercise is going to the fitness center or gym center such as Fitness First, Celebrity Fitness, CHI Fitness and etc. For those who are unable to discipline themselves in regular exercise is to pay for these fitness centers to force themselves to exercise. Fitness center provide special class for example body pump, body combat, yoga and etc.

For schooling kids, there are physical education classes twice a week in the time table. Students just need to pay attention to the PE class and enjoy the class. If the students are very active can take part in any others co-curriculums after school that needs a lot of activities for example sports society. Students should maintain physically active daily as part of play, games, sports work, transportation, recreation, physical education or planned exercise, in the context of family, school and community activities.
There is a main point that shown student or adults are inactive of transport especially in urban area, mainly students going to school by personal car or school bus. Only small percentage will use public transport such as bus or LRT. Even adult will prefer to drive than having public transport as the public transport maybe more expensive than driving. Besides that, time consuming is also an issue for us to avoid public transport. Therefore, we could not have chance to exercise by using public transport (it provide us chances of walking from station to school or work place).
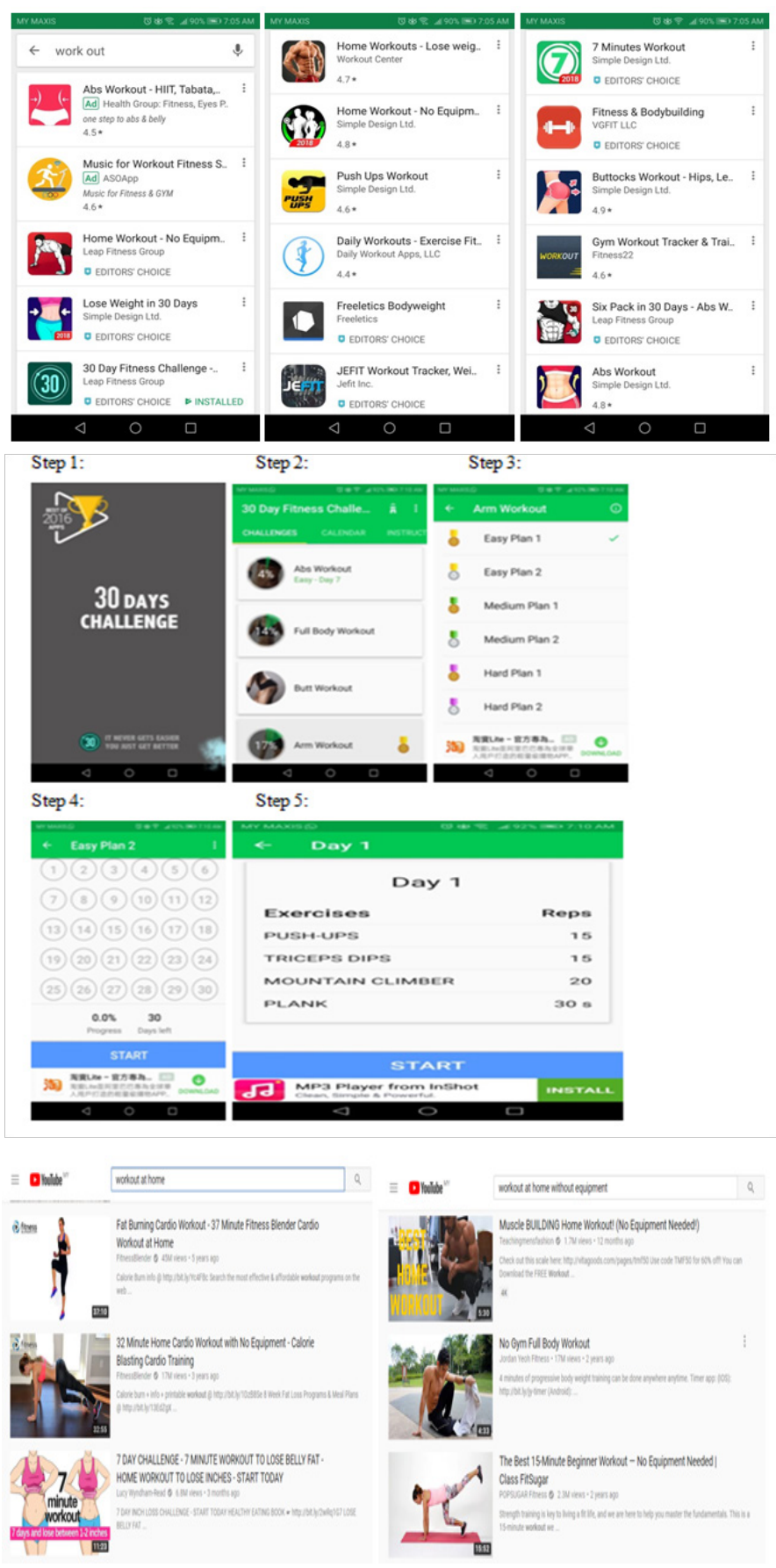

Figure I Types of Physical activities. 


\section{Where to have physical activities?}

For those who are eager to carry out physical activity, any place can be a place for exercise. Even if they are working in the office, there is a simple stretching exercise in the office. Nowadays, homes area starts to have gym room or in the playground area provide simple gym equipment for public to enjoy (Figure 2).
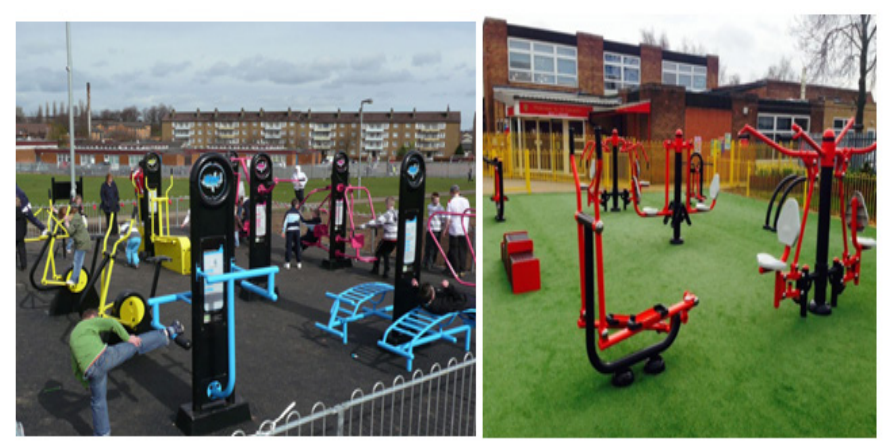

Figure 2 Where to have physical activities?.

\section{Physical activity recommendation for general population}

The Physical Activity Guidelines for Americans ${ }^{10}$ recommends that all adults should avoid inactivity and do at least 150 minutes a week (5 days x 30 minutes per day) of moderate-intensity, or 75 minutes a week of vigorous-intensity aerobic physical activity for substantial health benefits (Figure 3). ${ }^{11-14}$

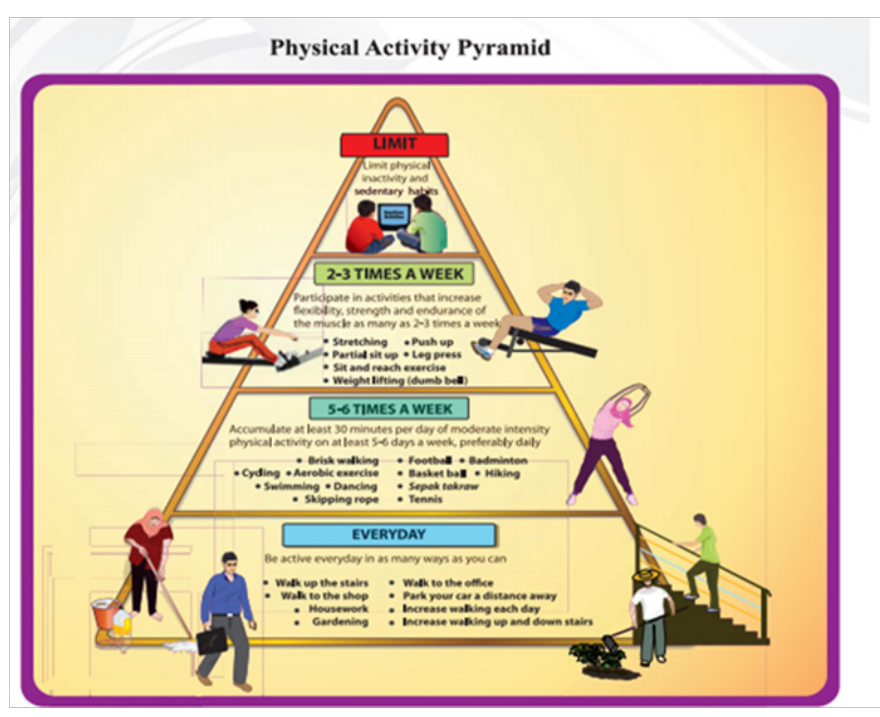

Figure 3 Physical activity Pyramid.

\section{Conclusion}

Physical activity is important to our life, but the first step is the hardest. However, if we can overcome it, maintain an exercise for 21 days continuously, Healthy life will accompany us forever. According to Malaysian Dietary Guidelines, to gain a healthy life just need to remember the key recommendation as below:

i. Be active every day in as many ways as you can.

ii. Accumulate at least 30 minutes of moderate intensity physical activity on at least five to six days a week, preferably daily.

iii. Participate in activities that increase flexibility, strength and endurance of the muscles, as frequent as 2 to 3 times a week.

iv. Limit physical inactivity and sedentary habits.

\section{Acknowledgements}

None.

\section{Conflict of interest}

Author declares that there is no conflicts of interest.

\section{References}

1. Malaysia's obesity rate highest in Asia, has technology led to our widening waistlines?. 2018.

2. Kenneth RF. The influence of physical activity in mental well-being. Public Health Nutr. 1999;2(3A):411-418.

3. http://www.moh.gov.my/images/gallery/Garispanduan/diet/KM3.pdf

4. US department of health and human services. Physical activity and health: a report of the surgeon general atlanta. 1996.

5. Caspersen CJ, Powell KE, Christenson GM. Physical activity, exercise and physical fitness: definition and distinctions for health-related research. Public Health Reports. 1985;100(2):126-131.

6. Andersen LB, Harro M, Sardinha LB. Physical activity and clustered cardiovascular risk in children: a cross-sectional study (The european youth heart study). Lancet. 2006;368(9532):299-304.

7. Chodzko ZWJ, Proctor ND, Fiatarone SMA, et al. Exercise and physical activity for older adults. Med Sci Sports Exerc. 2009; 41(7):1510-1530.

8. World Health Organization. world health report: shaping the future. world health organization analysis of prospective cohort studies. British Journal of Sports Medicine. 2003;42:238-243.

9. Welk GJ. Physical activity assessments for health-related research. Human Kinetics. 2002.

10. http://iku.moh.gov.my/images/IKU/Document/REPORT/MANS2003/ Volume6-PhysicalActivity.pdf

11. https://www.nst.com.my/news/nation/2017/06/246538/malaysiansmost-obese-region.7.6.2018

12. https://www.malaymail.com/s/1053569/nearly-half-malaysiaspopulation-overweight-or-obese-health-minister-says

13. http://www.who.int/ncds/prevention/physical-activity/en/

14. https://www.k-state.edu/kines/kineseducation/whatispa.html 